\title{
Bioinspired Total Synthesis of Bussealin $\mathbf{E}$
}

\author{
David G. Twigg, Leonardo Baldassarre, Elizabeth C. Frye, Warren R. J. D. Galloway, David R. Spring* \\ Department of Chemistry, University of Cambridge, Lensfield Road, Cambridge, CB2 1EW, U.K.
}

Supporting Information Placeholder

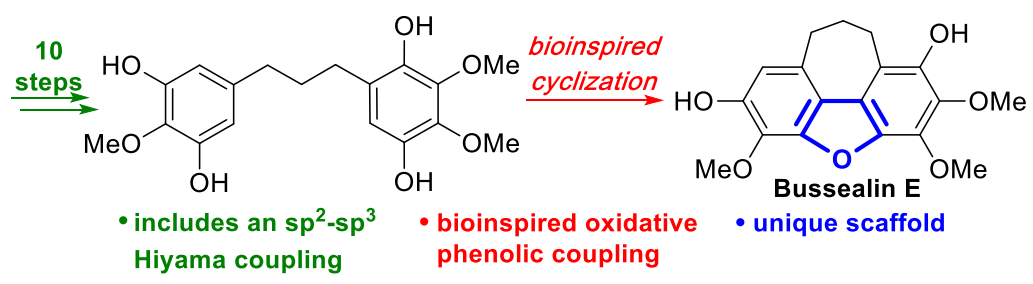

\begin{abstract}
The first total synthesis of bussealin E, a natural product with a unique cycloheptadibenzofuran scaffold, is reported. A strategy inspired by a proposed biosynthesis was employed, whereby a diphenylpropane derivative underwent an oxidative phenolic coupling to forge the tetracyclic ring system. The synthesis of the diphenylpropane featured a key sp ${ }^{2}-\mathrm{sp}^{3}$ Hiyama coupling between a vinyldisiloxane and a benzylic bromide.
\end{abstract}

First isolated in 2007 from the roots of the endemic Malagasy plant Bussea sakalava, the bussealin natural products consist of four diphenylpropanes (A-D) and a cycloheptadibenzofuran (E, 1, Figure 1) which display moderate antiproliferative activity against the A2780 human ovarian cancer cell line ( $\mathrm{IC}_{50} 24-45$ $\mu \mathrm{M}) .{ }^{1}$ More thorough biological assessment has been hampered by insufficient material and expedient synthetic routes are required to investigate this natural product family further. In light of this, the first total synthesis of bussealin A was reported in 2012 , with biological profiling indicating similar low- $\mu \mathrm{M}$ levels of activity against two other cancer cell lines. ${ }^{2}$ Of the other family members, bussealin $\mathrm{E}$ is notable for its unique carbon skeleton, with no other reported natural product bearing the same tetracyclic core. This structural novelty, alongside the potential biological applications of this unexplored system, suggested bussealin $\mathrm{E}$ as a target for total synthesis.

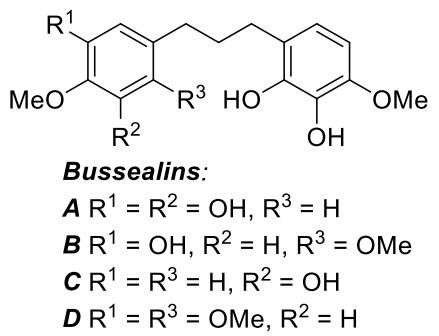

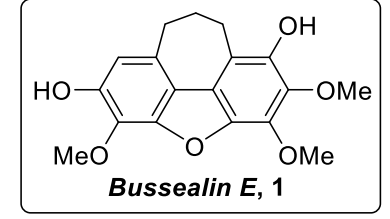

- Unique tetracyclic core

- Limited natural source

- $A 2780 / C_{50} 45 \mu \mathrm{M}$
Figure 1. The bussealin natural products.

Noting that bussealin E was found alongside several diphenylpropanes, Pan et al. proposed a biosynthetic route featuring the oxidative cyclisation and subsequent dehydration of an appropriately substituted intermediate 2 (Scheme 1A). ${ }^{1}$ With such a biomimetic approach deemed attractive, our retrosynthetic analysis focussed on diphenylpropane species 2 .

Scheme 1. Proposed biosynthesis (A) and retrosynthesis (B) of bussealin E 1
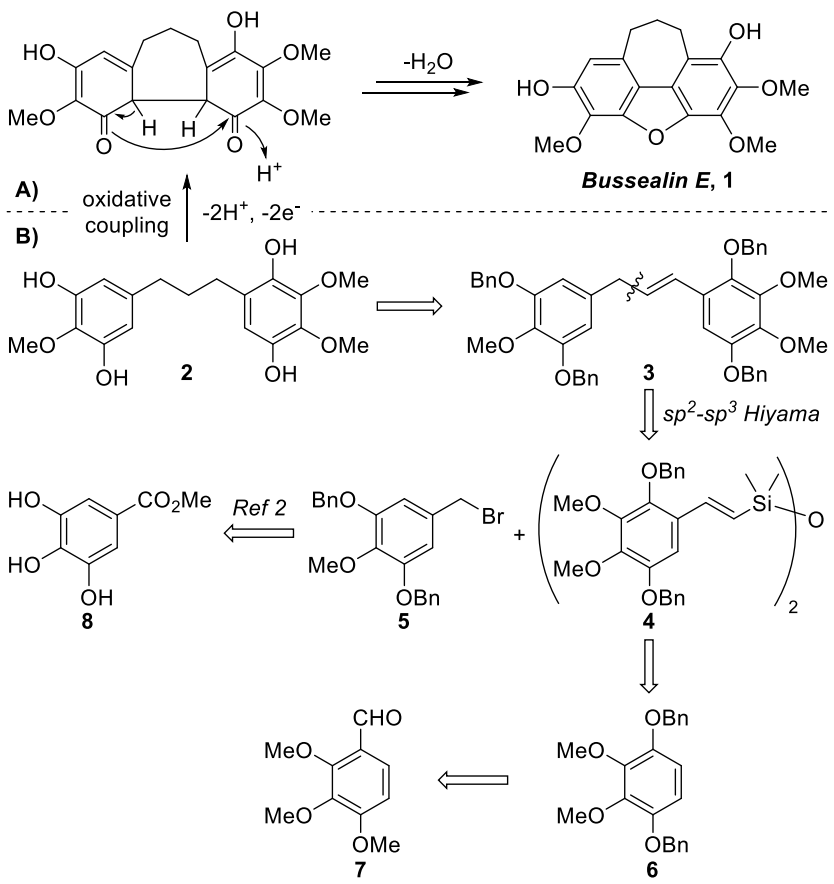

Using analogous disconnections to those employed in the synthesis of bussealin $\mathrm{A},{ }^{2}$ it was anticipated that $\mathbf{2}$ could be generated from the corresponding protected olefin $\mathbf{3}$, which we envisaged accessing via an $\mathrm{sp}^{2}-\mathrm{sp}^{3}$ Hiyama coupling of disiloxane 
4 with benzyl bromide 5; a reliable and atom-economical methodology previously developed in these labs (Scheme 1B). ${ }^{2,3}$ It was anticipated that the sequence of bromination, Sonogashira coupling and hydrosilylation would deliver the disiloxane 4 from symmetrical tetra-ether $\mathbf{6}$, itself accessible in multi-gram quantities from readily available 2,3,4-trimethoxybenzaldehyde $\mathbf{7}$ using established protocols. The synthesis of bromide $\mathbf{5}$ from methyl gallate $\mathbf{8}$ has been described previously. ${ }^{2}$

Scheme 2. Synthesis of alkyne intermediate 12

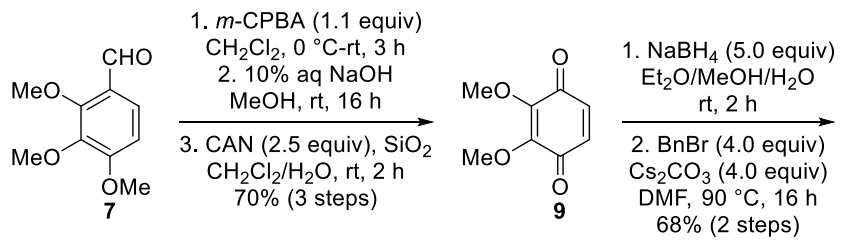

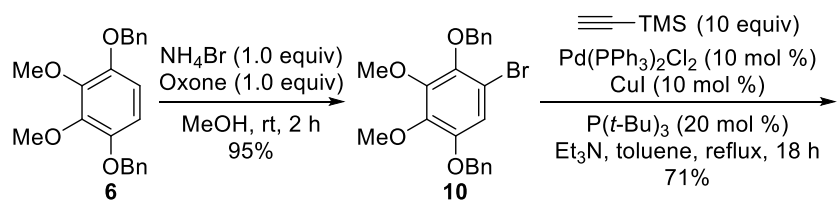

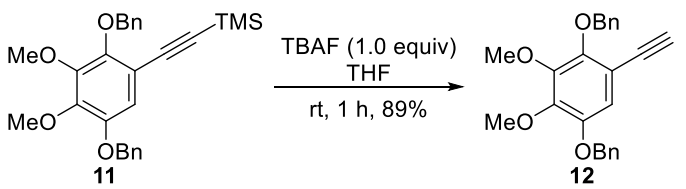

Synthetic efforts began with a Baeyer-Villiger oxidation of aldehyde 7 , followed by hydrolysis of the crude formate ester. Subsequent oxidation of the intermediate phenol using ceric ammonium nitrate on silica provided 2,3-dimethoxy-1,4-benzoquinone 9 (Scheme 2). Reduction with $\mathrm{NaBH}_{4}$ and bis-protection of the resultant hydroquinone with benzyl bromide proceeded smoothly to furnish tetra-ether intermediate $\mathbf{6}$. Bromination was achieved in a near quantitative yield using the conditions of Krishna Mohan et al. (Oxone, $\left.\mathrm{NH}_{4} \mathrm{Br}\right)^{4}$ to yield $\mathbf{1 0}$, which then underwent Sonogashira cross-coupling with trimethylsilylacetylene and subsequent deprotection of the silyl group to give the desired terminal alkyne $\mathbf{1 2}$ in a combined $63 \%$ yield. The Sonogashira coupling required relatively high catalyst loadings (10 mol \% $\mathrm{Pd}\left(\mathrm{PPh}_{3}\right)_{2} \mathrm{Cl}_{2}$ and $\left.\mathrm{CuI}\right)$ and an elevated temperature, possibly due to the electron-rich nature of the aryl bromide 10. Intermediate purification of the trimethylsilyl-protected alkyne $\mathbf{1 1}$ was also found to improve the overall yield compared to a one-pot procedure which only gave the desired product 12 in $44 \%$ yield from bromide $\mathbf{1 0}$.

Scheme 3. Synthesis of key diphenylpropane 2
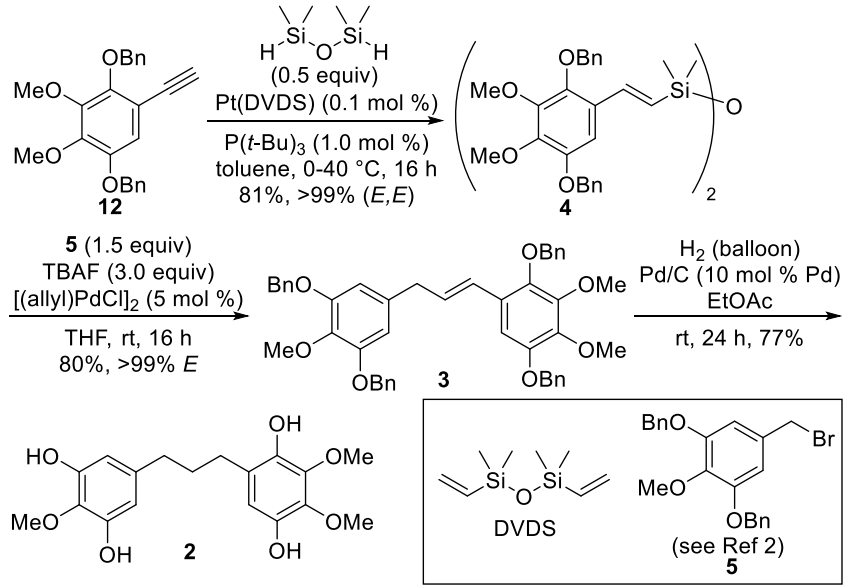

Pt-catalysed hydrosilylation of alkyne 12, as per the conditions of Denmark et al., ${ }^{5}$ generated the desired $(E, E)$ isomer of disiloxane 4 in excellent yield and geometric purity (Scheme 3 ). Pleasingly, the key $\mathrm{sp}^{2}-\mathrm{sp}^{3}$ Hiyama coupling of disiloxane 4 and benzyl bromide $\mathbf{5}$ (prepared in four steps from readily available methyl gallate $\mathbf{8}$, see Ref 2), proceeded in $80 \%$ yield and with complete retention of the olefin stereochemistry, with no evidence of the $\alpha$ isomer occasionally formed in such reactions. ${ }^{6}$ Catalytic hydrogenation of $\mathbf{3}$ over palladium on carbon then served to reduce the olefin and remove the four benzyl ether protecting groups, generating the desired tetraphenol species 2.

With 2 in hand, investigation of the proposed oxidative phenolic coupling towards bussealin E commenced. A range of oxidants have previously been used to effect similar intramolecular cyclisations. ${ }^{7}$ However, no examples featuring a 1,4-hydroquinone have been reported. Nevertheless, diphenylpropane 2 was subjected to a range of conditions, including: metal salts such as $\mathrm{MoCl}_{5},{ }^{8} \mathrm{SnCl}_{4},{ }^{9} \mathrm{VOF}_{3},{ }^{10} \mathrm{~Pb}(\mathrm{OAc})_{4},{ }^{11} \mathrm{FeCl}_{3}{ }^{12}$ and the TMEDA complex of $\mathrm{CuCl}(\mathrm{OH}) ;{ }^{13}$ hypervalent iodine species $\mathrm{PhI}(\mathrm{OAc})_{2}$ and $\mathrm{PhI}\left(\mathrm{O}_{2} \mathrm{CCF}_{3}\right)_{2} ;{ }^{14}$ and the organic oxidant, 2,3dichloro-5,6-dicyano- $p$-benzoquinone (DDQ) ${ }^{15}$ In all cases, a complex mixture of products was obtained, with the predominant species consistently observed by NMR analysis to be acyclic benzoquinone $\mathbf{1 3}$ (arising from oxidation of the corresponding 1,4-hydroquinone moiety of 2) and the spirocyclic species 14, which exists as a 3:1 mixture in solution with its hemiacetal isomer 15 (Scheme 4). Desired product 1 was only observed in trace amounts in some of these reactions, as assessed by comparing the analytical HPLC traces of the crude reaction mixtures against a reference sample of natural bussealin E (kindly provided for analysis by Prof. D. Kingston, Virginia Polytechnic Institute and State University). Of the reagents evaluated, $\mathrm{FeCl}_{3}$ gave the most promising result in this regard; further exploration of this oxidant was carried out by varying temperature and reagent stoichiometry, and including or excluding an acidic additive. Gratifyingly, the use of $\mathrm{FeCl}_{3}$ adsorbed onto silica gel, as employed by Jempty et al. ${ }^{16}$ followed by heating with paratoluenesulfonic acid produced a sufficient amount of bussealin E 1 to isolate an analytically pure sample, albeit in a low yield. Whilst further attempts to improve this result were not successful, the ${ }^{1} \mathrm{H}$ and ${ }^{13} \mathrm{C}$ NMR spectra of the synthetic material closely matched those previously reported for the natural sample (see SI), confirming its identity.

Scheme 4. Synthesis and proposed mechanism of formation of bussealin E 1
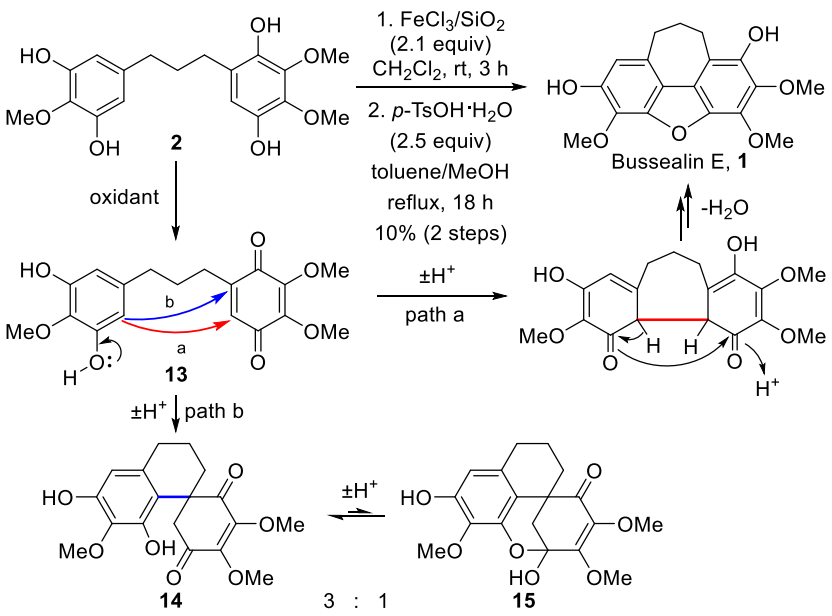
The concomitant observation of the previously mentioned by-products 13 and 14 provides new insights into the possible biosynthesis of bussealin $\mathrm{E} \mathbf{1}$. These results suggest a mechanism for the formation of $\mathbf{1}$ from $\mathbf{2}$ that proceeds via intramolecular Michael addition of initially generated benzoquinone 13, with formation of the smaller 6-membered spirocyclic ring (path b, Scheme 4) favoured over that of the 7-membered carbocycle (path a, Scheme 4), as evidenced by the reactions in this report. One previous publication demonstrates a similar result for an analogous diphenylethane system. ${ }^{17}$ When heated strongly in an acidic solution, an isolated sample of compound 14 did not undergo any change, with no observed rearrangement or retro-Michael reaction, suggesting 14 exists as a thermodynamically stable species. Alongside this observation, the low isolated yield of $\mathbf{1}$ may suggest that the reaction relies on an enzyme-catalysed process when formed naturally in order to generate appreciable quantities of the natural product.

In conclusion, we have completed the first reported synthesis of the unique cycloheptadibenzofuran natural product, bussealin E. The final intermediate in the synthesis, diphenylpropane 2, was prepared in 11 steps, in its longest linear sequence, in an overall $14 \%$ yield, featuring a key $\mathrm{sp}^{2}-\mathrm{sp}^{3}$ Hiyama coupling between a vinyldisiloxane and a benzylic bromide. The final bioinspired cyclisation to deliver bussealin $\mathrm{E}$ only proceeded in low yield, with the observed by-products suggesting a mechanism that proceeds via Michael addition of the initially formed 1,4-benzoquinone $\mathbf{1 3}$ with selectivity for the undesired 6-membered ring as seen in compound 14. This low yield could suggest that the reaction relies on an enzyme-catalysed process when formed naturally. With a route to bussealin E determined, further synthetic studies and biological evaluation of this novel scaffold are underway and will be reported in due course.

\section{ASSOCIATED CONTENT}

\section{Supporting Information}

The Supporting Information is available free of charge on the ACS Publications website.

Experimental details and characterization data for all products including ${ }^{1} \mathrm{H}$ and ${ }^{13} \mathrm{C}$ NMR spectra (PDF)

\section{AUTHOR INFORMATION}

\section{Corresponding Author}

*E-mail: spring@ch.cam.ac.uk

\section{Notes}

The authors declare no competing financial interest.

\section{ACKNOWLEDGMENT}

This research was supported by the EPSRC, BBSRC, MRC, Wellcome Trust, and ERC (FP7/2007-2013; 279337/DOS). D.G.T. thanks AstraZeneca for funding. D.R.S. acknowledges support from a Royal Society Wolfson Research Merit award. We thank Prof. D. Kingston (Virginia Polytechnic Institute and State University, U.S.A.) for providing a sample of authentic bussealin E. Data accessibility: all data supporting this study are provided as Supporting Information accompanying this paper.

\section{REFERENCES}

(1) Pan, E.; Harinantenaina, L.; Brodie, P. J.; Miller, J. S.; Callmander, M. W.; Rakotonandrasana, S.; Rakotobe, E.; Rasamison, V. E.; Kingston, D. G. I. J. Nat. Prod. 2010, 73, 1792-1795.

(2) Frye, E. C.; O' Connor, C. J.; Twigg, D. G.; Elbert, B.; Laraia, L.; Hulcoop, D. G.; Venkitaraman, A. R.; Spring, D. R. Chem. - Eur. J. 2012, 18, 8774-8779.

(3) (a) Sore, H. F.; Boehner, C. M.; Laraia, L.; Logoteta, P.; Prestinari, C.; Scott, M.; Williams, K.; Galloway, W. R. J. D.; Spring, D. R. Org. Biomol. Chem. 2011, 9, 504-515. (b) Sore, H. F.; Boehner, C. M.; MacDonald, S. J. F.; Norton, D.; Fox, D. J.; Spring, D. R. Org. Biomol. Chem. 2009, 7, 1068-1071. (c) Boehner, C. M.; Frye, E. C.; O'Connell, K. M. G.; Galloway, W. R. J. D.; Sore, H. F.; Garcia-Dominguez, P.; Norton, D.; Hulcoop, D. G.; Owen, M.; Turner, G.; Crawford, C.; Horsley, H.; Spring, D. R. Chem. - Eur. J. 2011, 17, 13230-13239.

(4) Krishna Mohan, K. V. V.; Narender, N. Synthesis 2012, 15-26.

(5) Denmark, S. E.; Wang, Z. Org. Lett. 2001, 3, 1073-1076.

(6) (a) Yoshida, J.; Tamao, K.; Yamamoto, H.; Kakui, T.; Uchida, T.; Kumada, M. Organometallics 1982, 1, 542-549. (b) Denmark, S. E.; Choi, J. Y. J. Am. Chem. Soc. 1999, 121, 5821-5822.

(7) Taylor, W. I.; Battersby, A. R. Oxidative Coupling of Phenols; M. Dekker, Inc.: New York, 1967.

(8) Kramer, B.; Fröhlich, R.; Waldvogel, S. R. Eur. J. Org. Chem. 2003, 3549-3554.

(9) Takeya, T.; Doi, H.; Ogata, T.; Otsuka, T.; Okamoto, I.; Kotani, E. Tetrahedron 2004, 60, 6295-6310.

(10) Kupchan, S. M.; Dhingra, O. P.; Kim, C.-K. J. Org. Chem. 1978, 43, 4076-4081.

(11) Feldman, K. S.; Ensel, S. M.; Minard, R. D. J. Am. Chem. Soc. 1994, 116, 1742-1745.

(12) Bolm, C.; Legros, J.; Le Paih, J.; Zani, L. Chem. Rev. 2004, 104, 6217-6254.

(13) Ohishi, T.; Kojima, T.; Matsuoka, T.; Shiro, M.; Kotsuki, H. Tetrahedron Lett. 2001, 42, 2493-2496.

(14) (a) Zhdankin, V. V.; Stang, P. J. Chem. Rev. 2002, 102, $2523-$ 2584. (b) Pouységu, L.; Deffieux, D.; Quideau, S. Tetrahedron 2010, 66, 2235-2261.

(15) Bohmdorfer, S.; Patel, A.; Gille, L.; Netscher, T.; Mereiter, K.; Rosenau, T. Curr. Org. Synth. 2013, 10, 165-168.

(16) (a) Jempty, T. C.; Miller, L. L.; Mazur, Y. J. Org. Chem. 1980, 45, 749-751. (b) Jempty, T. C.; Gogins, K. A. Z.; Mazur, Y.; Miller, L. L. J. Org. Chem. 1981, 46, 4545-4551.

(17) Thangaraj, S.; Tsao, W.-S.; Luo, Y.-W.; Lee, Y.-J.; Chang, C.F.; Lin, C.-C.; Uang, B.-J.; Yu, C.-C.; Guh, J.-H.; Teng, C.-M. Tetrahedron 2011, 67, 6166-6172. 